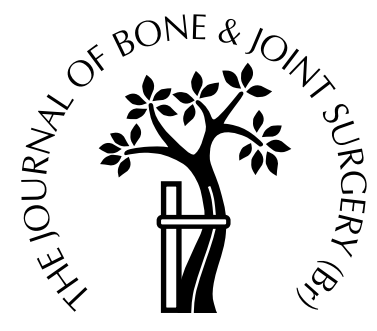

\title{
Timing of the administration of tranexamic acid for maximum reduction in blood loss in arthroplasty of the knee
}

\author{
N. Tanaka, H. Sakahashi, E. Sato, K. Hirose, T. Ishima, S. Ishii \\ From Sapporo Medical University, Japan
}

W

Te studied 99 patients who were undergoing total knee arthroplasty (TKA) to determine the optimum protocol for the administration of tranexamic acid (TNA) in order to reduce blood loss. It decreased by more than $40 \%$ after the administration of TNA. The haemostatic effect was greatest when TNA was given preoperatively and on deflation of the tourniquet. There was no increase in the incidence of adverse affects in the patients receiving TNA, compared with a control group.

We conclude that two injections of TNA, one given preoperatively and one on deflation of the tourniquet, significantly reduce blood loss without increasing the risk of thromboembolic complications.

J Bone Joint Surg [Br] 2001;83-B:702-5.

Received 22 September 2000; Accepted after revision 26 February 2001

Total knee arthroplasty (TKA) may be associated with considerable blood loss and transfusion carries significant risks of an immunological reaction and the transmission of disease.

Fibrinolysis is stimulated by surgical trauma, ${ }^{1,2}$ and further augmented by the use of a tourniquet. ${ }^{3-6}$ Despite intraoperative haemostasis, blood loss after TKA may be related to increased fibrinolytic activity, particularly during and immediately after operation. Tranexamic acid (TNA) inhibits fibrinolysis by blocking the lysine-binding sites of plasminogen to fibrin. ${ }^{7}$ The use of high doses of TNA during surgery has been recommended. Since continuous administration of TNA could conceivably increase the

N. Tanaka, MD

H. Sakahashi, MD

E. Sato, MD

K. Hirose, MD

T. Ishima, MD

Sapporo Gorinbashi Orthopaedic Hospital, Gorinbashi Health Care Facilities and Hospitals, 2-1 Kawazoe, Minami-ku, Sapporo, Hokkaido 005-0802, Japan.

S. Ishii, MD

Department of Orthopaedic Surgery, School of Medicine, Sapporo Medical University, Sapporo, Japan.

Correspondence should be sent to Dr N. Tanaka.

(C)2001 British Editorial Society of Bone and Joint Surgery 0301-620X/01/511745\$2.00 incidence of thromboembolic disease because of the potential haemostatic properties of TNA it is clearly important to determine the optimum time for its administration in order to achieve the maximum reduction of blood loss. In this study, we have evaluated the haemostatic effect of TNA by examining the differences in three groups of patients undergoing TKA who were given it by intravenous injection either once before operation, once on deflation of the tourniquet, or at both times, with a further group of patients who did not receive the drug.

\section{Patients and Methods}

The study was approved by the Ethics Committee at our hospital and all the patients gave their written informed consent. We enrolled 99 patients with either rheumatoid arthritis ${ }^{8}$ or osteoarthritis ${ }^{9}$ who were to have a unilateral bicondylar cemented TKA. The exclusion criteria were a known allergy to TNA, preoperative hepatic or renal dysfunction, serious cardiac or respiratory disease, congenital or acquired coagulopathy, and a history of thromboembolic disease. Non-steroidal anti-inflammatory medication was discontinued at least 24 hours before surgery.

Pairs of ampoules, each containing $20 \mathrm{ml}$ of either TNA (Rikavarin $100 \mathrm{mg} / \mathrm{ml}$; Asahi Chemical Industry Co Ltd, Japan) or a placebo (physiological saline) were numbered and placed in envelopes at random by a pharmacologist. A slow intravenous injection of the contents of each ampoule, the constituents of which were known only to the pharmacologist, was given by the anaesthetist. The patients were given either: 1) saline twice, ten minutes before surgery and on deflation of the tourniquet (control group); 2) $20 \mathrm{mg} / \mathrm{kg}$ of TNA ten minutes before surgery and saline ten minutes before deflation of the tourniquet (preop TNA group); 3) saline ten minutes before surgery and $20 \mathrm{mg} / \mathrm{kg}$ of TNA ten minutes before deflation of the tourniquet (intraop TNA group); or 4) $10 \mathrm{mg} / \mathrm{kg}$ of TNA ten minutes before surgery and again ten minutes before deflation of the tourniquet (pre- and intraop TNA group).

A tourniquet was placed around the thigh and inflated to a pressure of 350 to $400 \mathrm{mmHg}$ after exsanguination. The same design of cemented knee prosthesis (Nex-gen; Zimmer, Warsaw, Indiana) was used in all patients. The medullary cavity was plugged with bone. At the end of the 
Table I. Details of the patients in all four groups

\begin{tabular}{|c|c|c|c|c|}
\hline & Control & Preop TA & Intraop TA & Pre- and intraop TA \\
\hline Number of patients & 26 & 24 & 22 & 27 \\
\hline Mean age in years (range) & $65(58$ to 70$)$ & $65(59$ to 70$)$ & $65(60$ to 71$)$ & 65 (59 to 69$)$ \\
\hline Male:female & $9: 17$ & $7: 17$ & $7: 15$ & $8: 19$ \\
\hline Mean weight in kg (range) & $61(45$ to 76$)$ & $60(45$ to 70$)$ & $60(45$ to 70$)$ & $60(40$ to 76$)$ \\
\hline Mean height in $\mathrm{cm}$ (range) & $159(142$ to 170$)$ & $160(142$ to 170$)$ & $160(148$ to 168$)$ & 159 (145 to 169$)$ \\
\hline Mean operating time in minutes (range) & $125(90$ to 160$)$ & $110(80$ to 150$)$ & $120(85$ to 155$)$ & $110(70$ to 150$)$ \\
\hline Mean tourniquet time in minutes (range) & $95(60$ to 110$)$ & $90(60$ to 120$)$ & $90(60$ to 110$)$ & $90(60$ to 120$)$ \\
\hline Rheumatoid arthritis & 10 & 11 & 10 & 13 \\
\hline Osteoarthritis & 16 & 13 & 12 & 14 \\
\hline
\end{tabular}

Table II. Mean (range) blood loss and transfusion requirements

\begin{tabular}{|c|c|c|c|c|}
\hline & Control & Preop TA & Intraop TA & Pre- and intraop TA \\
\hline Number of patients & 26 & 24 & 22 & 27 \\
\hline $\begin{array}{l}\text { Blood loss }(\mathrm{ml}) \\
\text { Apparent } \\
\text { Total }\end{array}$ & $\begin{array}{l}785(670 \text { to } 880) \\
1470(1056 \text { to } 2115)\end{array}$ & $\begin{array}{l}355(210 \text { to } 520) \\
776(393 \text { to } 1159)\end{array}$ & $\begin{array}{l}420(280 \text { to } 660) \\
896(495 \text { to } 1310)\end{array}$ & $\begin{array}{l}211(140 \text { to } 390) \\
528(252 \text { to } 925)\end{array}$ \\
\hline $\begin{array}{l}\text { Transfusion needs } \\
\text { RC-MAP units } \\
\text { Number of patients }\end{array}$ & $\begin{array}{l}2(1.5 \text { to } 2.0) \\
26(100 \%)\end{array}$ & $\begin{array}{l}0.5(0.0 \text { to } 1.5) \\
16(67 \%)\end{array}$ & $\begin{array}{l}1.0(0.0 \text { to } 1.0) \\
17(77 \%)\end{array}$ & $\begin{array}{l}0.5(0.0 \text { to } 1.0) \\
14(52 \%)\end{array}$ \\
\hline
\end{tabular}

procedure, the tourniquet was deflated and major bleeding controlled by diathermy before closure. One high-vacuum intra-articular drain was used. Physiotherapy was started on the first day after operation and the drain removed a day later.

The need for blood transfusion in patients undergoing TKA remains controversial. In 1988, the National Institutes of Health Consensus Conference ${ }^{10}$ on perioperative transfusion suggested appropriate criteria and guidelines, which formed the basis for transfusion in our study.

Apparent blood loss was determined by measuring the level of suction fluid and the changes in the weight of swabs. Blood volume was recorded in the drain after it had been removed. There is also a considerable amount of postoperative blood loss by extravasation into the tissues which is not evacuated by suction drainage. We therefore calculated the total blood loss according to the formula of Gross, ${ }^{11}$ which uses the maximum postoperative decrease in the level of haemoglobin adjusted for the weight and height of the patient. Blood transfusions were recorded as the number of red cell MAP units (red cells in solution containing mannitol, adenine and phosphate) prepared from $400 \mathrm{ml}$ of donor blood, ${ }^{12}$ although red cell MAP units prepared from $200 \mathrm{ml}$ or $400 \mathrm{ml}$ of donor blood were used in this study. The level of haemoglobin was recorded before and on the first, second, fourth and seventh days after operation.

Thromboembolic and other complications were noted during the hospital stay. As routine screening for thrombosis, all patients underwent bilateral radio-isotope venography (technetium-99m) between 7 and 14 days after surgery at which time standard perfusion lung-scan imaging was also performed. ${ }^{13}$

We used a one-way analysis of variance for statistical appraisal of the data.

\section{Results}

The four groups were comparable in age, gender, bodyweight, height, operating time, duration of tourniquet inflation and classification of disease (Table I).

Blood loss and transfusion requirements (Table II). The apparent and total blood losses in the groups receiving TNA were significantly lower than those in the control group with a mean level of 785 and $1470 \mathrm{ml}$, respectively $(\mathrm{p}<0.01)$. The mean apparent and total blood losses in the pre- and intraop TNA group were 211 and $528 \mathrm{ml}$, respectively, which were significantly lower than those in the other groups receiving TNA $(p<0.05)$. The mean apparent and total blood losses were lower in the preop TNA group than in the intraop TNA group, although the differences were not significant.

The parameters of the transfusion requirements (the mean red cell units and the number of patients requiring transfusion) were lower in the groups receiving TNA than in the control group $(2$ units $(\mathrm{p}<0.01)$ and 26 patients $(100 \%)$, respectively). In the pre- and intraop TNA group they were the lowest of those receiving TNA, being lower in the preop group than in the intraop group. The differences in transfusion requirements in the three groups receiving TNA were not significant.

Haemoglobin levels (Table III). There were no differences 
Table III. Mean (range; 95\% confidence interval) $\mathrm{Hb}$ concentrations before and after operation

\begin{tabular}{|c|c|c|c|c|}
\hline & Control & Preop TA & Intraop TA & Pre- and intraop TA \\
\hline Number of patients & 26 & 24 & 22 & 27 \\
\hline Preoperative $\mathrm{Hb}$ (g/dl) & $11.8(9.9$ to $13.6 ; 11.4$ to 12.3$)$ & $11.3(9.9$ to $13.6 ; 11.0$ to 12.4$)$ & $11.6(9.9$ to $12.6 ; 11.5$ to 12.7$)$ & $11.5(9.9$ to $14.5 ; 11.2$ to 12.8$)$ \\
\hline \multicolumn{5}{|l|}{ Postoperative $\mathrm{Hb}(\mathrm{g} / \mathrm{dl})$} \\
\hline Day 1 & 7.8 (7.0 to $11.6 ; 7.7$ to 8.9$)$ & 10.7 (8.6 to $12.0 ; 10.2$ to 11.1$)$ & $9.7(8.5$ to $11.8 ; 9.5$ to 11.5$)$ & $11.7(9.5$ to $13.4 ; 11.1$ to 12.0$)$ \\
\hline 2 & $9.7(8.0$ to $12.7 ; 9.5$ to 10.5$)$ & $9.4(8.0$ to $12.1 ; 9.1$ to 10.1$)$ & $9.2(7.5$ to $11.1 ; 9.0$ to 10.2$)$ & $11.1(9.0$ to $12.8 ; 10.6$ to 11.6$)$ \\
\hline 4 & $10.3(8.5$ to $12.6 ; 9.9$ to 10.8$)$ & $10.2(8.5$ to $12.1 ; 9.7$ to 10.5$)$ & $9.9(8.9$ to $11.8 ; 9.8$ to 10.8$)$ & $10.3(8.5$ to $12.6 ; 10.1$ to 11.1$)$ \\
\hline 7 & $10.6(9.2$ to $13.0 ; 10.4$ to 11.1$)$ & $10.3(9.4$ to $12.0 ; 9.7$ to 11.1$)$ & $10.4(9.1$ to $11.6 ; 9.8$ to 11.6$)$ & $11.0(9.4$ to $13.0 ; 10.8$ to 11.8$)$ \\
\hline
\end{tabular}

in the preoperative haemoglobin levels in the four groups. The minimum postoperative haemoglobin levels were significantly higher $(\mathrm{p}<0.05)$ in the preop TNA and intraop TNA groups on day two, and in the pre- and intraop TNA group on day four than in the control group on day one (mean, $7.8 \mathrm{~g} / \mathrm{dl}$ ). The minimum haemoglobin level in the pre- and intraop TNA group (mean; $10.3 \mathrm{~g} / \mathrm{dl}$ ) was significantly higher $(\mathrm{p}<0.05)$ than that in the other groups receiving TNA. The mean level of haemoglobin was higher in the preop TNA group than in the intraop TNA group (9.2 $\mathrm{g} / \mathrm{dl}$ ), although the difference was not significant.

Adverse events. There were no differences in the incidence of adverse events in the groups. One patient in each receiving TNA had mild nausea. No patient had clinical signs of deep-vein thrombosis or pulmonary embolism, and no other complications were noted.

Radio-isotope venography and ventilation-perfusion lung scanning. There were no differences in the findings of venography or of lung scanning in the four groups. Twelve of 26 patients (46\%) in the control group, 11 of $24(46 \%)$ in the preop TNA group, ten of $22(45 \%)$ in the intraop TNA group and 13 of $27(48 \%)$ in the pre- and intraop TNA group had positive findings on venography. None, however, had positive findings on lung scanning.

\section{Discussion}

There are four methods of administering TNA in order to reduce blood loss in TKA: intramuscular, oral, intravenous and intra-articular. The time taken for maximum plasma levels of TNA to be reached has been reported to be 30 minutes for intramuscular, two hours for oral, and 5 to 15 minutes for intravenous administration. ${ }^{14,15}$ Ahlberg, Eriksson and Kjellman ${ }^{16}$ found that TNA given intravenously diffused rapidly into the synovial fluid and membrane and thus there was no reason to inject it intra-articularly. An intravenous injection for patients undergoing TKA is the best method for rapidly raising and maintaining the therapeutic concentration of TNA ${ }^{7,17-22}$ in the knee during and after operation.

Pharmacokinetic studies ${ }^{14,15,20,23}$ indicated that a dose of $20 \mathrm{mg} / \mathrm{kg}$ of TNA is suitable for TKA since therapeutic levels can be maintained for approximately eight hours after operation, which covers the period of hyperfibrinolysis in cases of increased blood loss. ${ }^{24}$

Several clinical studies have shown the efficacy of TNA when given before surgery ${ }^{25,26}$ or on deflation of the tourniquet. $^{27,28}$

Two aspects were clarified in our study. First, the blood loss in TKA was decreased by more than $40 \%$ after the administration of TNA. The haemostatic effect was best when TNA was given once before surgery and once on deflation of the tourniquet. It was better when TNA was administered before operation rather than on deflation of the tourniquet. Thus, suppression of fibrinolysis from the beginning of the operation may be more effective than only at the time of the peak of hyperfibrinolysis later.

There remains uncertainty as to the place of antifibrinolytic drugs such as TNA in the clinical setting, although they may dramatically reduce blood loss, and particularly as to whether their use leads to an increase in the incidence of adverse events such as thromboembolism. A diagnosis of deep-vein thrombosis or pulmonary embolism should not be made unless clinical suspicion is confirmed objectively. In order to examine the postoperative incidence of thromboembolism, venography was performed at the time when the incidence of clinically evident thrombosis should be at its peak, between seven and 14 days after operation. ${ }^{29,30}$ There was no difference between the groups of patients receiving TNA and the control group.

The high frequency of positive venograms in all groups $(45 \%$ to $48 \%)$ is in agreement with other reports. ${ }^{29,30} \mathrm{~A}$ false-positive finding has been reported in $15 \%$ of patients. ${ }^{31}$ This requires further examination.

Two injections of TNA, one given preoperatively and one on deflation of the tourniquet, significantly reduce blood loss associated with cemented TKA performed with a tourniquet, without increasing the risk of thromboembolic complications.

No benefits in any form have been received or will be received from a commercial party related directly or indirectly to the subject of this article.

\section{References}

1. Risberg B. The response of the fibrinolytic system in trauma. Acta Chir Scand Suppl 1985;522:245-71.

2. Janssens M, Joris J, David JL, Lemaire R, Lamy M. High-dose aprotinin reduces blood loss in patients undergoing total hip replacement surgery. Anesthesiology 1994;80:23-9.

3. Kruithof EKO, Nicolosa G, Bachmann F. Plasminogen activator inhibitor 1: development of a radioimmunoassay and observations on its plasma concentration during venous occlusion and after platelet aggregation. Blood 1987;70:1645-53.

4. Nakahara M, Sakahashi H. Effect of application of a tourniquet on bleeding factors in dogs. J Bone Joint Surg [Am] 1967;49-A:1345-51. 
5. Klenerman L, Chakrabarti R, Mackie I, Brozovic M, Stirling Y. Changes in haemostatic system after application of a tourniquet. Lancet 1977;1:970-2.

6. Petaja J, Myllynen P, Myllyla G, Vahtera E. Fibrinolysis after application of a pneumatic tourniquet. Acta Chir Scand 1987;153:647-51.

7. Nilsson IM. Clinical pharmacology of aminocaproic and tranexamic acids. J Clin Pathol Suppl R Coll Pathol 1980;14:41-7.

8. Arnett FC, Edworthy SM, Bloch DA, et al. The American Rheumatism Association 1987 revised criteria for the classification of rheumatoid arthritis. Arthritis Rheum 1988;31:315-24.

9. Altman R, Asch E, Bloch D, et al. Development of criteria for the classification and reporting of osteoarthritis: classification of osteoarthritis of the knee. Arthritis Rheum 1986;29:1039-49.

10. National Institutes of Health Consensus Conference. Perioperative red blood cell transfusion. JAMA 1988;260:2700-3.

11. Gross JB. Estimating allowable blood loss: corrected for dilution. Anesthesiology 1983;58:277-80

12. Sasakawa S, Shiba M, Mura T, et al. Development of additive solution MAP for storage of red cell concentrates. Jpn J Transfusion Med 1991;37:398-403.

13. Angus PD, Nakielny R, Hoodlum DT. The pneumatic tourniquet and deep venous thrombosis. J Bone Joint Surg [Br] 1983;65-B:336-9.

14. Benoni G, Bjorkman S, Fredin H. Application of pharmacokinetics data from healthy volunteers for the prediction of plasma concentrations of tranexamic acid in surgical patients. Clin Drug Invest 1995;10:280-7.

15. Sano M, Hakusui H, Kojima C, Akimoto T. Absorption and excretion of tranexamic acid following intravenous, intramuscular and oral administrations in healthy volunteers. Jpn J Clin Pharmacol Therapeutics 1976;7:375-82.

16. Ahlberg A, Eriksson O, Kjellman H. Diffusion of tranexamic acid to the joint. Acta Orthop Scand 1976;47:486-8.

17. Astedt B. Clinical pharmacology of tranexamic acid. Scand J Gastroenterol Suppl 1987;137:22-5.

18. Verstraete M. Clinical application of inhibitors of fibrinolysis. Drugs 1985;29:236-61.
19. Andersson L, Nilsson IM, Colleen S, Granstrand B, Melander B. Role of urokinase and tissue activator in sustaining bleeding and the management thereof with EACA and AMCA. Ann NY Acad Sci $1968 ; 146: 642-58$

20. Walzman M, Bonnar J. Effects of tranexamic acid on the coagulation and fibrinolytic systems in pregnancy complicated by placental bleeding. Arch Toxicol Suppl 1982;5:214-20.

21. Maki M, Beller FK. Comparative studies of fibrinolytic inhibitors in vitro. Thromb Diath Haemorrh 1966;16:668-86.

22. Longstaff $\mathbf{C}$. Studies on the mechanisms of action of aprotinin and tranexamic acid as plasmin inhibitors and antifibrinolytic agents. Blood Coagul Fibrinolysis 1994;5:537-42.

23. Eriksson O, Kjellman H, Pilbrant A, Schannong M. Pharamacokinetics of tranexamic acid after intravenous administration to normal volunteers. Eur J Clin Phamacol 1974;7:375-80.

24. Howes JP, Sharma V, Cohen AT. Tranexamic acid reduces blood loss after knee arthroplasty. J Bone Joint Surg [Br] 1996;78-B:995-6.

25. Jansen AJ, Andreica S, Claeys M, et al. Use of tranexamic acid for an effective blood conservation strategy after total knee arthroplasty. Br J Anaesth 1999;83:596-601.

26. Sakahashi H, Sato E, Ishima T. A means for control of bleeding during and after the artificial knee joint replacement operation (combined use of antiplasmin and the drain clamp method). Jpn Soc Replacement Arthroplasty 1998;28:67-8.

27. Benoni G, Fredin H. Fibrinolytic inhibition with tranexamic acid reduces blood loss and blood transfusion after knee arthroplasty: a prospective, randomised, double-blind study of 86 patients. J Bone Joint Surg [Br] 1996;78-B:434-40.

28. Hiippala ST, Strid LJ, Wennerstrand MI, et al. Tranexamic acid radically decreases blood loss and transfusions associated with total knee arthroplasty. Anesth Analg 1997;84:839-44.

29. Salzman EW, Harris WH. Prevention of venous thromboembolism in orthopaedic patients. J Bone Joint Surg [Am] 1976;58-A:903-13.

30. Maynard MJ, Sculco TP, Ghelman B. Progression and regression of deep vein thrombosis after total knee arthroplasty. Clin Orthop 1991;273:125-30.

31. Verstraete M. The diagnosis and treatment of deep-vein thrombosis. N Engl J Med 1993;329:1418-20. 